\title{
El surgimiento del cooperativismo en el Perú: la Convención- Cusco ${ }^{1}$
}

\section{The emergence of cooperativism in Peru: the Convention- Cusco}

\section{Roxana Borda Mamani \\ Dirceu Basso ${ }^{\star *}$}

\begin{abstract}
Resumen: Las actuales cooperativas y asociaciones que aún persisten en La Convención cuentan con intensas luchas protagonizadas por los campesinos de la época, durante la década de 1940 a 1960, con el objetivo de mantenerse activos. Históricamente, el cooperativismo surge en Europa, en Gales a fines del siglo XVIII. Sin embargo, en el continente suramericano, caso peruano, la primera cooperativa cafetalera surge en la provincia de La Convención, ubicada en el departamento del Cusco. La cooperativa cafetalera emergió a partir del primer sindicato, organizado por campesinos a consecuencia de la violencia, la opresión, los precios injustos de los productos, del abuso y la esclavitud por parte de los hacendados. El objetivo del presente trabajo es analizar el proceso del surgimiento y creación de las cooperativas en el Perú, específicamente en la región del Cusco, debido a que la primera cooperativa histórica surge en esa región, que fue impulsada por los campesinos. La metodología adoptada será basada en la revisión bibliográfica.
\end{abstract}

Palabras claves: Cooperativismo. Campesinos. Luchas Sociales.

\begin{abstract}
The current cooperatives and associations that still persist in The Convention, has intense struggles carried out by the peasants of the time, during the decade of 1940 to 1960, with the objective of staying active. Historically, cooperativism emerged in Europe, in Wales at the end of the 18th century. However, in the South American continent, the Peruvian case, the first coffee cooperative, arises in the province of La Convención, located in the department of Cusco. The coffee cooperative, emerged from the first
\end{abstract}

\footnotetext{
${ }^{1}$ Uma versão preliminar deste texto foi apresentada no "II SEMINÁRIO INTERNACIONAL DE PÓS-GRADUAÇÃO EM DESENVOLVIMENTO RURAL SUSTENTÁVEL” em Foz do Iguaçu, entre 07 a 09 de agosto de 2019, sendo indicado pelo evento para compor este volume especial.

*Estudante do Curso de Desenvolvimento Rural e Segurança Alimentar (DRUSA) pela Universidade Federal da Integração Latino-Americana (UNILA). E-mail: rborbamamani@gmail.com.

** Doutor em Desenvolvimento Rural pela Universidade Federal do Rio Grande do Sul (UFRGS); Mestre em Desenvolvimento Rural pela UFRGS; Especialista em Planejamento Municipal e Qualidade Ambiental pela Universidade Estadual do Oeste do Paraná (Unioeste); Médico Veterinário pela Universidade Federal de Pelotas (UFPEL); Professor da Universidade Federal da Integração Latina-Americana (UNILA); E-mail: dirceu.basso@unila.edu.br.
}

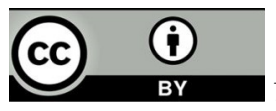


union, organized by farmers, as a result of violence, oppression, unfair prices to products, abuse and slavery by the landowners. The objective of this work, seeks to analyze the process of the emergence and creation of cooperatives in Peru, specifically in the region of Cusco, because the first historical cooperative emerged in this region, which was driven by farmers. The methodology adopted will be based on the bibliographic review.

Keywords: Cooperativism. Peasants. Social Struggles.

Recebido em 28/11/2019. Aceito em: 10/03/2020.

\section{Introducción}

El presente artículo tiene como objetivo contribuir con las reflexiones acerca de las experiencias cooperativistas desarrolladas en Perú por los agricultores familiares campesinos. Para eso, el estudio busca identificar cuales factores que explican la emergencia del cooperativismo en el país, con énfasis en las actividades asociadas al cultivo de café. El proyecto realizado se justifica a causa de los procesos de desarrollo rural visto que el cooperativismo tiene importante contribución en la mejoría de las condiciones de vida de las personas y consecuentemente de las familias.

El café fue y aún es uno de los principales productos agrícolas del Perú. La producción es principalmente realizada por agricultores familiares, organizados en asociaciones y cooperativas. Esas organizaciones contribuyen para diversas etapas de la cadena productiva, desde las actividades de reunir la producción hasta aquellas vinculadas a la comercialización en el exterior.

Dentro del contexto peruano, la historia sobre el surgimiento de las cooperativas en la región, inició con la presencia del sindicato de trabajadores de la hacienda de Maranura (BARRIGA, 2009). Según Mladenatz (2003, p. 62), "el origen de la cooperación está en el propio origen de la humanidad, en su modo de ser, vivir y actuar de acuerdo con las necesidades vitales". La interacción que existe entre las cooperativas y áreas rurales, urbanas permite el aprovechamiento de los recursos autóctonos; por ello, es posible afirmar que el cooperativismo constituye una vía de desarrollo local, porque el cooperativismo agrícola refuerza la idea de que la agricultura es el principal hecho de desarrollo rural. Se entiende por cooperativa aquella organización que nace por la iniciativa de los interesados que tienen objetivos en común, buscando el desarrollo; esa asociación representa una economía colectiva.

De acuerdo con Salas (2014, p. 22) los pequeños productores “[...] son en su gran mayoría campesinos que no tienen suficiente conocimiento de las instituciones formales. Esto infiere la importancia que se da a los acuerdos verbales [...]". Remy Simatovic (2007), citado por Salas (2014, p. 22), sostiene que conservan el legado que heredaron de sus ancestros de la cultura Inca. En ese sentido adquirieron la idea de la acción colectiva manteniendo un sistema de trabajo de reciprocidad familiar, en el cual los miembros de la comunidad ayudan a otros en sus tareas particulares. A esa idea se denominó en el Imperio como Ayni.

El cual se basa en la reciprocidad o mutualismo entre los campesinos. Es una práctica social al igual que la minka, que consiste en ayuda mutua, colectiva, comunitaria y, en algunos casos 
voluntarios, más exige la reciprocidad y compromiso por medio, por ejemplo, de donación de algún producto agrícola o simplemente a cambio de trabajo en la parcela del otro.

La historia de cómo surgen las cooperativas en La Convención - Cusco está llena de intensas luchas protagonizadas por los agricultores familiares campesinos (AFC) de la época. Durante los años 1952 a 1964, la provincia vivió una intensa lucha, teniendo alrededor de 33 huelgas, liderada por los campesinos, para hacer frente a la abolición de los hacendados y "arrendires". Con el tiempo, los denominados arrendires cumplirían el papel de los hacendados, por lo que se les empezó a llamar "capataces", quienes comenzaron a mantener una relación de explotación y sobreexplotación con los campesinos. Esto indica que el pueblo peruano se estaba esclavizando a sí mismo.

Entonces, la lucha no solo era contra los hacendados o terratenientes, sino también contra los capataces. A pesar de todo, los grupos de sindicatos de trabajadores campesinos continuaron su resistencia, se basaban en esta frase: "la unión hace la fuerza". Por ello, el campesino y político cusqueño Hugo Blanco impulsó y organizó las luchas sociales y tenía la idea de llevar la lucha por toda la región y nivel del estado, convirtiendo así en líder de la región (CRAIG,1968). En ese contexto, el movimiento sindical crea, en 1958, "la central campesina denominada Federación Provincial Campesina de La Convención" con el fin de exigir al gobierno mejores condiciones laborales [...]" (SALAS, 2014 p. 36). Logrando así que, en el año 1960, crear la primera cooperativa cafetalera Maranura de la región y del Perú (BARRIGA, 2009).

Además, el autor Remy Simatovicop (2007) citado por Salas, (2014, p. 36), enfatiza que los campesinos de La Convención, fueron los precursores de la reforma agraria del Perú. Asimismo, (SALAS, 2014, p. 36) recalca que La Central de Cooperativas Agrarias de la Convención y Lares (COCLA) antecede a la reforma agraria, siendo ésta la primera cooperativa de café del Perú; la consolidación de COCLA como una red se debe a aspectos culturales homogéneos.

La metodología adoptada para el siguiente trabajo será basada en la revisión bibliográfica. Para eso, fue desarrollado un plan de trabajo en que fueron definidos tema, objetivo, delimitación e importancia. Además, fue ejecutada la compilación del material sobre el asunto contenido en libros, revistas y sitios. Una vez organizado el material, fue realizado un registro con análisis y discusiones posteriores.

El resultado del estudio permite observar que, entre los factores que contribuyen para la emergencia del cooperativismo en Perú, en la Convención de Cusco, están: la percepción entre los agricultores campesinos sobre la importancia de la cooperación para la mejoría de las condiciones de vida y de producción; la organización sindical de los agricultores familiares campesinos; la opresión y la esclavización sufridas por los campesinos por parte de los hacendados; y la necesidad de ampliar la cooperación entre los agricultores, a partir de cooperativas, a fin de realizar las actividades productivas más allá de la producción, incluyendo el acceso a los mercados.

Además de la presente introducción, el artículo abarca el contexto histórico del cooperativismo. En la tercera parte, describe la emergencia del cooperativismo de Quillabamba - Perú y, en fin, presenta las consideraciones finales.

\section{Contexto histórico general del cooperativismo}

El cooperativismo tiene su historia desde la antigüedad “esclavitud”. Gromoslav Mladenatz (2003) argumenta que los romanos y griegos trabajaban basadas en la ayuda mutua, por ejemplo, los pequeños artesanos de funerarias. Sin embargo, Otto Jurista (s.f.), citado por Mladenatz (2003), 
de la historia del derecho cooperativo en los pueblos germánicos asentó las bases cooperativas, las cuales prevalecen hasta nuestros tiempos, por ejemplo, la creación de las ovejas, los ganados, el arado de la tierra, la cosecha, son algunas prácticas que aún perduran en el medio rural, porque son sociedades conservadoras y tradicionales.

El profesor Johann Friedrich Schär (s.f.), citado por Mladenatz, (2003, p. 20), fue uno de los dirigentes del movimiento cooperativismo suizo. En la edad media, por ejemplo, se desarrolló movimientos de cristianos en relación a las organizaciones económicas de los monasterios, teniendo un punto de vista integral, donde la producción y el consumo se hacían en común. Las ideas sobre el cooperativismo surgieron a mediados del siglo XV hasta mediados del XVII y esos pensadores o precursores son los que sentaron las bases sobre los conceptos que hoy conocemos. Los grandes utopistas surgieron en Inglaterra y Francia, porque en esos lugares fue donde comenzaron los grandes avances de desarrollo industrial, la imprenta, etc.

Entre ellos, citado por Mladenatz (2003, p. 17-74), tenemos a P. C. Plockboy e John Bellers que aportan con la importancia de la formación de la doctrina cooperativista y de los grupos económicos que están formados por cuatro categorías de individuos que son: agricultores, artesanos etc. y, cada individuo, recibirá un crédito como dinero, tierra. Ese proyecto dio como resultado la relación entre la agricultura y la industria en una economía colectiva.

Sin embargo, Robert Owen (1771-1858) es considerado padre del cooperativismo, pero tuvo una vida de trabajo desde niño y, con el tiempo, se convirtió en empresario y socialistautópico británico que llevó a la práctica sus ideas reformistas; primero en su fábrica y luego en las colonias. Para Owen, buscar el beneficio y unos de los males fundamentales del hombre, porque beneficio es igual a la inequidad (objeto del beneficio es el dinero). Mientras tanto, Doctor William King (1780-1865), considerado como el precursor de los cristianos-sociales, también aporta una concepción económica del cooperativismo: "que la organización del trabajo y en el interés de aquellos que proveen el trabajo” (MLADENATZ, 2003, p. 44).

\section{La cuna del cooperativismo en la región de Quillabamba - Perú}

La Provincia de La Convención fue creada por Ley el 25 de julio del 1857 durante el gobierno de Mariscal Ramón Castilla y Marquezado. En 1881, Don Martín Pío Concha sede la tercera parte de su hacienda para la instalación de la ciudad de Quillabamba (capital actual de La Provincia) (BARRIGA, 2009).

La Convención es una de las 13 provincias, ubicada en el departamento del Cusco, a una altitud de 1050 msnm, con una "población" de 147148 habitantes. La Provincia de La Convención cuenta con 14 distritos y se caracterizan por su clima tropical, húmedo y la producción de café, cacao, achiote y frutas. Son pequeños productores campesinos, la superficie promedia de café es de 3,53 has. La principal fuente de mano de obra es la familia, seguida de la ayuda mutua denominada, en el idioma quechua, “Ayni" (DUVAL, 2008, p. 16).

Antes de la llegada de los españoles, las tierras convencianas fueron habitadas por pueblos indígenas de la región, siendo en su mayoría etnias machiguengas y otros grupos, los cuales se fueron desplazando hacia el interior de la amazonia convenciana, debido al avance de los colonizadores españoles, criollos y en la época de los Incas (BARRIGA, 2009). Después de la captura del Tupac Amaru en Vilcabamba, el virrey ordena a que se reorganice la ciudad y la repartición de tierras. Posteriormente, en el año 1572, se fundó la ciudad de San Francisco de La Victoria, siendo militares los propietarios. 
Las haciendas surgen con la presencia de las órdenes misioneras, donde se tuvo cultivo de caña de azúcar y extracción minera, más estas fracasaran a mitad del siglo XVII. Sin embargo, las haciendas resurgirán después de la independencia de la república en el siglo XIX.

A inicios del siglo XX, mediante la ley de "tierras de montaña", hubo una ola de migración hacia el interior y, como consecuencia, el resurgimiento de los latifundios, pero el territorio se encontraba en manos de hacendados, los cuales demandaban mano de obra, un motivo más para migrar al interior. Fue así que, en 1933, llega la carretera a la provincia, gracias al trabajo de los inmigrantes, esclavos, yanaconas. Un año antes, 1932, se desató la epidemia de malaria, donde se tuvo un alto nivel de mortandad. Por ello, la inmigración hacia la provincia “[...] sólo se reanudó a partir de 1940 por motivos de trabajo, en el que los hacendados cedieron pequeñas parcelas por un determinado tiempo a cambio de trabajar en sus propiedades” (BARRIGA, 2009, p. 9).

La migración de campesinos se vinculaba con la hacienda, bajo la forma de "arrendire", que era una forma particular de tenencia de tierra. Así, los inmigrantes trabajaban en las tierras de los hacendados por un determinado tiempo. Las actividades que se tenían en esa época eran producción de cacao, caña de azúcar, té, café y agua ardiente. Los arrendires laboraban bajo las siguientes condiciones:

Condición de turno: el trabajo de unos días al mes en los terrenos del hacendado a cambio de un pago muy escaso. Palla: se mandaba a las mujeres a pallar (cosechar) café, té, coca, entre otros. Maquipura: trabajar en los terrenos del hacendado a cambio de un pago mínimo. Faenas: trabajos en reparaciones de caminos, limpieza de acequias. No se recibía paga, pero el hacendado debía proveer comida y bebida (BARRIGA, 2009, p. 9).

Esas formas de trabajo que ejercían los campesinos lo realizaban porque no tenían acceso a la tierra, trabajan por subsistir y alimentar a sus familias. También existía abuso de autoridad por parte de hacendados y capataces, por ejemplo: algunos no podían explorar el bosque, pues sólo era para traer leña, los productos eran comercializados por la hacienda, pagaban por cada animal (burro, mula, caballo), el derecho de hierbaje, se prohibía hacer estudiar a los hijos fuera de la ciudad, producir otros productos que hacen daño la producción de la hacienda, etc. bajo un contrato por 10 años.

Entonces sino cumples esa condición el hacendado sigue juicio, entonces ha ganado el hacendado y venía a sus casas con todas sus gentes y venía a llevar a la carretera sus cosas [...] El juicio que no ha cumplido condición, entonces esa chacra que te ha dado te quita y a otro da, a otro trabajador, como te ha botado a la carretera, tienes que ir nomás. Entrevista a Felipe Borda, socio fundador de cooperativa Maranura (BARRIGA, 2009, p. 10).

En consecuencia, a los abusos de autoridad, se creó el primer sindicato el 20 de abril do 1947, en la hacienda de Maranura, el cual ya contaba con un secretario de cooperativas. Todavía, entre los años 50 y 51, se disuelve por temor a represión por parte del gobierno militar de Manuel Odría. "El movimiento sindical, se reanudó en el año de 1957, donde surgieron otros sindicatos en las haciendas como: Chaullay, Uchumayo, Paltaibamba, Huyro, Poroncoy, Chinche, Echarate, Quellouno, Pan de Azúcar, Cocabambilla y San Pedro" (BARRIGA, 2009, p. 15).

A partir de la década de los 50, la producción de café tuvo mayor dinamismo, porque la demanda pelo producto iba en aumento y también las características geográficas y climáticas favorecían el pleno desarrollo y producción. Con la expansión del ferrocarril que llegó al distrito 
de Santa Teresa, surgió un nuevo actor, los comerciantes “intermediarios”, donde se podría hacer un trato directo, por ejemplo: un adelanto (préstamo) que condiciona la entregar del producto, que permitió tener un grado de autonomía (BARRIGA, 2009).

En el año 1958 fue creado la central campesina denominada "Federación Provincial Campesina de La Convención", con una base de 15 sindicatos organizados, con aproximadamente 10000 a 11000 campesinos "ex yanaconas", participaron en la lucha por la posición de tierra e independencia de los hacendados (CRAIG, 1968). Los campesinos realizaron las manifestaciones hacia los hacendados; negándose a trabajar en sus tierras, organizados mediante los sindicatos, el cual se reflejó en todas "las haciendas, donde se pedía la reducción de condiciones, horas de trabajo, libre comercio" (CRAIG, 1968, p. 2). Después de las manifestaciones, en 1960 fue creado la primera cooperativa cafetalera "Maranura" de la región y del Perú. De acuerdo con (BARRIGA, 2009, p. 27), "ésta no se encuentra registrada como la primera cooperativa debido a errores de registro siendo por el contrario la Cooperativa Cafetalera San Juan del Oro en Puno, la que goza de este título". Históricamente, el cooperativismo surgió en La Convención, por ello, la cooperativa de Maranura, emerge en medio de luchas sindicales, posteriormente se consolidó, para hacer frente a los intermediarios que compraban los productos a bajo precio, ya que las cooperativas se forman con la finalidad de lograr mejores condiciones de comercialización, mediante la venta en conjunto.

Por otro lado, Camacho e Morote (2012) mencionan que el gobierno impulsó la formación con el objetivo de pacificar la zona en conflicto entre campesinos y comerciantes. En 1962, el gobierno de la junta militar promulgó la Ley 14.444, ley de la Reforma Agraria, que exigía el pago por las tierras asignadas al campesino, y no al arrendatario. Sin embargo, la ley no tuvo aceptación ya que era injusta para los campesinos, el cual conllevo a que se suscitasen movilizaciones sindicales direccionadas por Hugo Blanco, que fue uno de los líderes de la organización de los sindicatos en las haciendas. Tras intensas luchas, en 1962 se logró la legitimidad de titulación de las parcelas que tenían un área de 3 a 5 hectáreas, libre de abolición. Así, "[...] en el término de diez escasos años; caía abatido un sistema feudal de relaciones sociales de 300 años de existencia, siendo reemplazado por campesinos organizados independientes, dedicados al cultivo del café, que les era pagado en efectivo" (CRAIG, 1968, p. 3). Por ello, en 1963 el presidente Fernando Belaúnde promulgó el Decreto Ley 15.037, que expropiaba todas las tierras de las haciendas que eran trabajadas por campesinos, y solo fue aplicada en esta región, debido a las demandas de los campesinos que luchaban por sus tierras. Entonces se procedió oficialmente anular las anteriores relaciones contractuales existentes entre el hacendado y sus yanaconas (los trabajadores).

Según Craig (1968), se había logrado así, un desarrollo autónomo de la región y construyendo un fenómeno latinoamericano que tenía una organización de abajo hacia arriba un sindicato de trabajadores rurales en lugar de ser dirigido y originado desde afuera. "Como resultado del proceso, la región pasó de ser una estructura tradicional de relaciones sociales basadas en el sistema de hacienda, a un nuevo sistema de minifundios, donde cada agricultor era independiente de sus anteriores amos" (CRAIG,1968, p. 3). Ante el aumento de la producción del café, los yanaconas comenzaron a crear estrategias de cómo mejorar su producción y muchos granjeros empezaron a reclamar los terrenos.

En ese tiempo, nació la cooperativa de financiamiento, como una entidad privada que cumplió la función de banco/que fungió como banco, y permitió a los agricultores, tener acceso a préstamos para llevar a cabo su producción, como por ejemplo pedir préstamos de dinero para la financiación para pagar a los trabajadores en la cosecha de café, té, cacao, limpieza, etc. 
La Cooperativa de Ahorro y Crédito Quillabamba Ltda. Nro 295 se constituyó el 23 de mayo del 1964, inscrita en el Registro Nacional de Cooperativas de Crédito y en el Registro de Asociaciones de los Registros Públicos del Cusco. En cumplimiento de lo dispuesto en la Ley General de Cooperativas, la cooperativa modifica su estatuto el once de agosto del 2001. [...] La misión es promover el desarrollo económico y social de nuestros socios, brindando soluciones financieras, con solidaridad, sostenibilidad, calidad y responsabilidad; mientras que la visión es ser la cooperativa de ahorro y crédito líder a nivel nacional, que brinda productos innovadores, como un modelo exitoso del cooperativismo peruano. Por lo que está haciendo, no está muy lejos de su visión. La Cooperativa [...] es una asociación autónoma de personas que se han unido voluntariamente para hacer frente a sus necesidades y aspiraciones económicas, sociales y culturales comunes por medio de una institución financiera de propiedad conjunta y democráticamente controlada (MARTINEZ, 2018, p. 1).

Esta cooperativa fue la pionera de la región, y trabajo con el agricultor. Muchos hicieron préstamos durante la época, para poder conseguir trabajar y financiar la producción del producto principal que es el café y otros como té, cacao, coca, etc.

Después, las cooperativas se fueron desvinculando de los sindicatos, para ser instituciones, para que en el año 1967, se creara la Central de Cooperativas Agrarias de la Convención y Lares (COCLA), a raíz de las 7 cooperativas como: Agrícola y de Servicios Sicre Ltda., N99; Cooperativa Agrícola y de Servicios del Sindicato de Huadquiña Ltda., N¹09; Cooperativa Agrícola y de Servicios Huayopata Ltda. N¹10; Cooperativa Campesina Túpac Amaru Ltda. N¹15; Cooperativa Campesina Mateo Pumacahua Ltda. $\mathrm{N}^{\circ} 185$; Cooperativa Agrícola y de Servicios Valle de Lares Ltda. N¹86; Cooperativa Agrícola Santa Ana Ltda. N²32, (BARRIGA, 2009). La consolidación de COCLA, fue el indicio de la victoria que lograron los campesinos, mediante las luchas sindicales organizadas por ellos. De acuerdo con (SALAS, 2014, p. 31),

(...) la formación de COCLA, precede a la reforma agraria del gobierno militar y nace de la iniciativa de los pequeños productores. Buscando fundamentalmente, solucionar el problema de la comercialización del café, el cual estaba sujeto al capricho de los comerciantes, que recibían el café a consignación, sin garantía de un precio justo para los productores.

Eguren (2006) comenta sobre la reforma agraria del Perú como una de las radicales que tuvo en la América del Sur, pues fue un período muy complejo desde el punto de vista social, organizacional. Además, tuvieron movimientos campesinos que luchaban por la reivindicación de su cultura que fue impuesta y tuvo migración de la periferia hacia el centro y concentración de tierras.

\section{Consideraciones finales}

El estudio permitió observar la dinámica del cooperativismo en Perú, realizada por los agricultores familiares campesino en la implementación de la cultura del café, en la Convención - Cusco, durante las décadas de 1940 a 1960.

En respuesta a la pregunta que sirvió de orientación para el estudio, o sea, cuales podrían ser los factores que contribuirían en la explicación de la emergencia del cooperativismo en el país, pueden ser destacadas las siguientes: la percepción entre los agricultores campesinos 
sobre la importancia de la cooperación para construir sus proyectos de vida y de producción; la capacidad de se organizaren en esferas sindicales en cuanto una importante herramienta de lucha; la percepción, en cuanto sujeto, de la situación de opresión y esclavización en las relaciones vivenciadas con los hacendados; y la necesidad de ampliar las prácticas de cooperación entre los agricultores por medio de las cooperativas en diferentes niveles, para poder actuar en las diversas etapas de la cadena productiva de sus productos objetivando más renta y cualidad de vida de las familias. El estudio evidenció, como idea síntesis, que las cuestiones presentes y que dieron base para el inicio del movimiento cooperativo moderno en los siglos pasados son similares aquellas que condujeron la emergencia del cooperativismo en la región del estudio en Perú. Ese facto social contó con las capacidades obtenidas por los campesinos, de la región del estudio, de estimular diversas instituciones (sindicatos, federación, cooperativa singular y cooperativa central) que desempeñaron papel fundamental en sus luchas sociales.

La cooperativa de COCLA, en cuanto resultado del proceso de luchas de los campesinos, actualmente está conformada por 22 cooperativas primarias, ubicada en los Valles de La Convención y Yanatile, cerca de la ciudad Inca de Machu Picchu entre los 800 y 2.000 metros sobre el nivel del mar (BARRIGA, 2009). Actualmente, es la central de cooperativas más grande del Perú en término de asociados y en cuanto a su volumen de exportación está ubicada en el cuarto lugar del ranking de exportadores de café en el Perú. Así, la consolidación de COCLA es un indicio de victoria que lograron los campesinos mediante las luchas sindicales organizadas por ellos.

Por fin, nuevas cuestiones son colocadas en cotidiano de las familias campesinas y en sus organizaciones, lo que exige colocar nueva demanda de estudio. Delante de grandes y profundas transformaciones que viven las sociedades en los días actuales, con destaque para los mercados globales, y las tecnologías de informaciones, son sugeridos nuevos estudios en el sentido de verificar como esas cooperativas, tanto las primarias cuanto la central (COCLA), están conseguido garantizar y, al mismo tiempo, ampliar las condiciones de vida y de producción de sus asociados. En otras palabras, como las cooperativas están conseguido contribuir en el desarrollo rural de la región del estudio.

\section{Referencias bibliográficas}

BARRIGA, P. R. F. Funcionamiento de cooperativas cafetaleras y su impacto en la vida familiar de sus asociados: casos de familias de dos sectores de la provincia de La Convención vinculadas a la Cooperativa Maranura y a la central de cooperativas COCLA. 2009. $236 \mathrm{f}$. Tesis (Licenciatura en Antropología) - Facultad de Ciencias Sociales, Pontificia Universidad Catolica del Peru, Lima, 2009.

CRAIG, W. El movimiento campesino en La Convención: la dinámica de una organización campesina. Lima: Instituto de estudios peruanos, Série Documentos Teóricos, n. 11, 1968.

CAMACHO, L. E. S.; MOROTE, N. I. M. La ocupación temprana en La Convención, selva alta de Cusco. Investigaciones Sociales, Lima - Perú, v. 16, n. 28, p. 167-184, 2012.

DUVAL, L. Estudio de los efectos y del impacto del comercio justo certificado en el Perú y en República Dominica: Estudio en la organización de productores COCLA, Perú. France: FBE, ene. 2008.

EGUREN, F. Reforma agraria y desarrollo rural en el Perú. Rural Finance \& Investment Learning Centre, Lima, 2006. Disponible en: <http://www.ruralfinanceandinvestment.org/sites/default/ files/1248203802936_01__eguren_peru.pdf>.Accesado el 22 jun.2019.

MLADENATZ, G. História das doutrinas cooperativistas. Brasília: Editora Confebras, 2003. 
MARTINEZ, C. S. Prestigiosa Institución Cusqueña está logrando éxitos em el Cusco. Micro Finanzas, Lima - Perú, ene. 2018. Disponible en: <https://microfinanzas.pe/2017/index.php/2018/enero/567prestigiosa-institucion-cusquena-esta-logrando-exitos-en-el-cusco>. Accesado el 20 mai. 2019.

SALAS, C. P. Subsistema estrictamente coordenado de café: central de cooperativas agrarias de La Convención y lares "COCLA". 2014. 52 f. Tesis (Especialista en Agronegocios y Alimentos) - Facultad de Agronomía, Universidad de Buenos Aires, Buenos Aires, 2014. Disponible en: <http://ri.agro.uba.ar/ files/download/tesis/especializacion/2014salaspenacarlos.pdf>.Accesado el 25 jun. 2019. 